\title{
A Comparative Study of the Icephobic and Self-Cleaning Properties of Teflon Materials Having Different Surface Morphologies
}

\author{
E. Vazirinasab, K. Maghsoudi*, R. Jafari, G. Momen \\ Department of Applied Sciences, University of Quebec in Chicoutimi (UQAC) \\ 555, boul. de l'Université, Chicoutimi, Québec, G7H 2B1, Canada \\ *E-mail: Khosrow.maghsoudil@uqac.ca
}

\begin{abstract}
Materials having fluorocarbon bonds are among the best candidates for the fabrication of superhydrophobic surfaces. Here, we describe two facile, non-expensive, and industrialized approaches to produce superhydrophobic Teflon materials having ultra-water repellency, icephobic, and self-cleaning properties. Direct replication and plasma-treatment approaches produced Teflon sheets having very different surface patterns, i.e. microstructures and micronanostructures. Neither approach altered the chemical composition of the original Teflon surfaces. Rice leaf-like microstructures were produced on the replicated surface, whereas lotus leaf-like hierarchical micro-nanostructures characterized the plasma-treated surface. Water droplets rolled off the micro-nanostructured surfaces $\sim 10 \%$ faster than off the microstructured surfaces. The micro-nanostructured surface also produced more rebounds for a water droplet during the impact test. Although both surfaces possessed similar self-cleaning properties, the micro-nanostructured surface reduced ice adhesion to a greater degree than the microstructured surface. The more
\end{abstract}


effective ice repellency of the micro-nanostructured surface was due to its surface morphology that reduced the interlocking of ice inside the surface asperities. However, the microstructured surface delayed considerably the onset of freezing of a water droplet due to the larger micro-air pockets trapped within its surface asperities.

Keywords: Teflon surface, icephobic, self-cleaning, surface morphology, freezing delay, ice adhesion reduction

\section{Introduction}

Icing phenomena on outdoor equipment such as transmission cables, aircraft, wind turbines, and telecommunication towers can lead to their mechanical failure and their becoming safety hazards. To reduce this damage to vulnerable outdoor infrastructure, attempts have been made to create anti-icing/icephobic surfaces [1-8]. Icephobic surfaces are normally defined by an ice adhesion strength of $<100 \mathrm{kPa}$ [9]. In reality, two main categories of de-icing and anti-icing techniques exist and differ in their ice adhesion requirements. The first is composed of active methods where thermal or mechanical energy is used to de-ice. The second represents passive methods where no external energy is applied [10]. For the passive removal of ice, a much lower ice adhesion strength $(<20 \mathrm{kPa})$ is required [9].

Superhydrophobic surfaces having a water contact angle (WCA) $>150^{\circ}$ and a contact angle hysteresis $(\mathrm{CAH})<10^{\circ}$ can be created through a combination of low surface energy materials and micro- and/or nanostructured surface topography [11]. This combination leads to the trapping of air pockets in the depressions on the surface and produces a composite air-liquid-solid interface. This interface increases WCA and decreases CAH to produce a Cassie-Baxter state [12]. Such non-wetting surfaces are among the best candidates for delaying ice formation and reducing the 
energy needed for de-icing. Superhydrophobic surfaces having various surface roughnessmicrostructures, nanostructures, hierarchical structures - demonstrate different icing behaviors during both ice formation and de-icing [13-21]. These various icing behaviors are due to (a) the amount of heat transfer through the trapped air in between the surface asperities $[13,15]$, (b) the effect of surface roughness on the heterogeneous nucleation rate of ice at the water-solid interface $[13,19]$, and (c) the interlocking of created ice within the surface asperities [17, 20, 21].

Over the last decade, multiple approaches have been used to create superhydrophobic surfaces [2235]. The direct replication and plasma-treatment methods are compatible with industrial applications. They do not require complex engineering procedures or a long fabrication time [22, 36, 37]. Moreover, these approaches can fabricate superhydrophobic surfaces on a wide range of materials $[38,39]$. Polytetrafluoroethylene (PTFE) is a polymer that has extremely low surface energy $\left(18.6 \mathrm{mN} / \mathrm{m}\right.$ at $20{ }^{\circ} \mathrm{C}$ [40]) making PTFE a promising candidate for fabricating superhydrophobic surfaces [5, 41-44]. Previous studies have described creating superhydrophobic surfaces using a PTFE coating generated by sputtering [45-47]. Here, however, we focus on the fabrication of superhydrophobic PTFE materials, e.g. Teflon sheets, films, composites [48].

We employed two different facile, low-cost methods to produce self-cleaning and icephobic Teflon materials through the processes of direct replication and atmospheric pressure plasma. Although using a plasma technique is a commonly applied method for creating superhydrophobic PTFE materials, it has always been limited to non-atmospheric low-pressure plasma, e.g. $\mathrm{Ar}, \mathrm{CF}_{4}, \mathrm{~N}_{2}$, and $\mathrm{O}_{2}$ plasmas $[49,50]$. To the best of our knowledge, neither atmospheric pressure plasma nor direct replication has yet been used for producing icephobic and self-cleaning PTFE materials. Through our novel approach, we obtained two very different surface morphologies, i.e. microstructured rice leaf-like grooves by direct replication and hierarchical micro-nanostructured 
lotus leaf-like pattern by plasma treatment. Despite similar self-cleaning abilities, the structures differed in their icing behaviors.

\section{Materials and methods}

\subsection{Fabrication of superhydrophobic Teflon surfaces}

Superhydrophobic samples were produced using Teflon ${ }^{\circledR}$ (Groupe POLYALTO, QC, Canada) sheets of $30 \mathrm{~mm} \times 50 \mathrm{~mm} \times 2 \mathrm{~mm}$. We produced the templates for the direct replication using aluminum alloy 5052 and a wet chemical etching method. The etching was carried out by submerging the template in a $10 \mathrm{wt} . \%$ hydrochloric acid $(\mathrm{HCl})$ solution for $20 \mathrm{~min}$. The etched templates were then cleaned ultrasonically using a mixture of acetone, ethanol, and distilled water to remove any residual particles from the surface.

A press machine (Carver Inc., USA) was used for the direct replication of created patterns on the Teflon surfaces. The machine has two temperature-controllable platens, and the temperature range varies from ambient temperature to $350{ }^{\circ} \mathrm{C}$. The platen temperatures were set at $280{ }^{\circ} \mathrm{C}$, and the Teflon sheet was placed on the lower platen to soften. After $5 \mathrm{~min}$, the aluminum template was placed carefully on the Teflon sheet and the platens were fastened using a hydraulic pump. A pressure of $170 \mathrm{kPa}$ was applied for $10 \mathrm{~min}$ to soften the Teflon sheet and therefore replicate the aluminum template patterns faithfully. After this step, the platens were opened, and the Teflon sheet was detached from the template.

An AS400 atmospheric pressure plasma machine (Plasmatreat GmbH, Germany) working in the pulsed mode was employed to create structures on the Teflon sheets. We used compressed air as it is an abundant and inexpensive plasma gas. The flow rate was set at $2000 \mathrm{~L} \cdot \mathrm{h}^{-1}$. The speed of 
the movable plasma jet was $2 \mathrm{~m} \cdot \mathrm{min}^{-1}$. We fixed the distance between the plasma nozzle and substrate at $8 \mathrm{~mm}$ and set the plasma frequency at $21 \mathrm{kHz}$. As the system works in a pulsed mode, the pulsed power-cycle time was set at 100, which represents an equal time of being on and off.

\subsection{Surface characterization and water-repellency properties}

We relied on scanning electron microscopy (SEM) (JSM-6480 LV SEM manufactured by JEOL Japan) to observe the surfaces of the produced surfaces. To enhance imaging quality, the Teflon surfaces were coated with a thin layer of gold-palladium alloy prior to analysis. To better observe surface topography, we used a $25^{\circ}$ angle view for each measurement. An optical profiler (Profil3D Filmetrics, USA) measured surface roughness. The line and area roughness values were calculated based on ASME B46.1 2D and ASME B46.1 3D standards, respectively.

WCA and CAH were determined using a Kruss ${ }^{\mathrm{TM}}$ DSA100 goniometer set at $25 \pm 0.5^{\circ} \mathrm{C}$. A $4-\mu \mathrm{L}$ deionized (DI) water droplet was deposited onto the sample surface, and we measured the WCA using the Young-Laplace approximation. The $\mathrm{CAH}$ was defined as the difference between the advancing and receding contact angles when the water droplet moved on the surface. We measured WCA at five points on each sample, and we repeated each measurement five times to ensure accuracy. We report the average value and standard deviation for each sample. To evaluate whether our approaches altered the chemical composition of the Teflon surfaces, we used a Cary 630 Fourier transform infrared spectroscopy (FTIR) Spectrometer (Agilant, USA) in ATR (attenuated total reflection) mode to analyze the chemical functions of the produced surfaces.

Water repellency was evaluated through droplet roll-off and impact tests. We assessed the behavior of water droplets rolling off surfaces that were inclined at $10^{\circ}$. Using a syringe, a water droplet was placed gently onto the surface. The droplet had no initial velocity. 
Water droplet impacts were recorded using a high-speed camera (FASTCAM SA1.1 by Photron) at a framing rate of $5400 \mathrm{fps}$, and all impact experiments were conducted at a constant temperature of $22{ }^{\circ} \mathrm{C}$. The DI water droplets had a volume of $20-\mu \mathrm{L}$ with a diameter of ca. $3.4 \mathrm{~mm}$ and were released with zero initial velocity from $12 \mathrm{~cm}$ above the surface.

\subsection{Icephobic and self-cleaning properties}

Icephobic properties of the produced samples were determined using a homemade push-off instrument. This test measures the shear stress at which ice is detached from the surface. The selected approach is particularly useful where small samples or more complicated geometries are tested. In this test, a thin cylindrical plastic mold, 1-cm in diameter, is placed on the substrate and then filled with DI water to form an ice cylinder by remaining in a cold chamber at $-10{ }^{\circ} \mathrm{C}$ for 24 $\mathrm{h}$ prior to the testing. The test sample is then placed on the holder and fixed by two screws (Fig. 1). By starting the test using a remote computer-controlled interface, the motor turns the screw at a fixed rate of $0.05 \mathrm{~mm} \cdot \mathrm{s}^{-1}$ so that the sample holder is pushed gradually toward the force gage. The force gage measures the shear force ten times per second until the ice is detached. Therefore, the adhesion stress can be calculated by knowing the maximum force and the icing area.

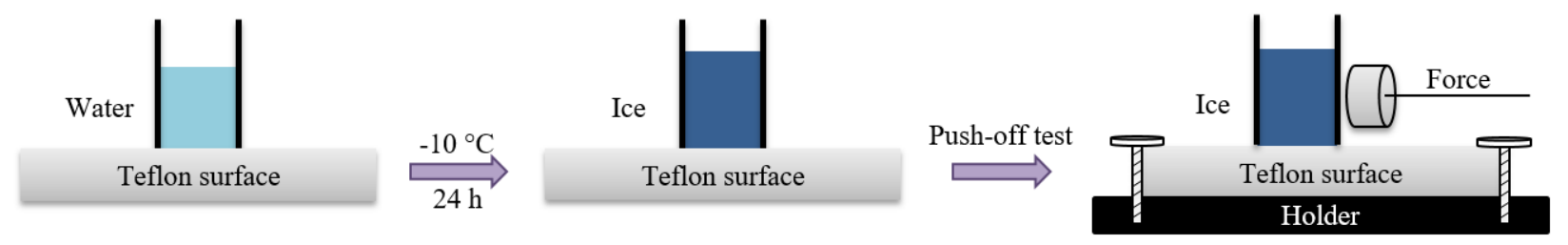

Fig. 1. Schema of the push-off test procedure.

The freezing delay time was determined using the cold chamber of the Kruss ${ }^{\mathrm{TM}}$ DSA100 goniometer where sample stage temperature can reach $-30{ }^{\circ} \mathrm{C}$. 
To assess the self-cleaning properties of the produced Teflon surfaces, we applied kaolin powder having a chemical composition of $\mathrm{Al}_{2} \mathrm{Si}_{2} \mathrm{O}_{5}(\mathrm{OH})_{4}$ as the artificial contaminant. Equal amounts of kaolin powder were scattered homogeneously on the pristine, replicated, and plasma-treated Teflon surfaces using a 60-mesh sieve. Prior to conducting the self-cleaning test, the kaolin powder was allowed to set onto the surface for $30 \mathrm{~min}$. We then used a water droplet fixed to a syringe needle tip to sweep the kaolin powder off the Teflon surface at a speed of $16.6 \pm 0.1 \mathrm{~cm} \cdot \mathrm{s}^{-1}$. The images were captured by a high-quality digital camera (PowerShot SX50 HS, Canon).

We also examined the self-cleaning abilities of the produced superhydrophobic Teflon surfaces through the cleaning of a dried droplet containing a solution of several contaminants. We prepared a $24-\mathrm{g} \cdot \mathrm{L}^{-1}$ dirty solution consisting of carbon black, kaolin, and salt in water for use as a contaminant. The solution was thoroughly mixed for $1 \mathrm{~h}$, and before any sedimentation could occur, a droplet was placed gently onto each surface using a syringe to release ca. 3-mm-diameter droplets. The surfaces were then dried under ambient conditions for $3 \mathrm{~h}$ to evaporate the water and then cleaned with water droplets.

\section{Results and discussion}

\subsection{Surface morphology}

The surface morphology of the produced surfaces was examined using scanning electron microscopy. SEM images show the different surface roughness created on the Teflon surfaces by the direct replication method and plasma treatment. Compared to the pristine Teflon surface (Error! Reference source not found.a), the replicated Teflon surface (Error! Reference source not found.b) possesses microstructured patterns set by the aluminum template, whereas the 
plasma-treated Teflon surface (Error! Reference source not found.c) obtained very different patterns of surface structure.
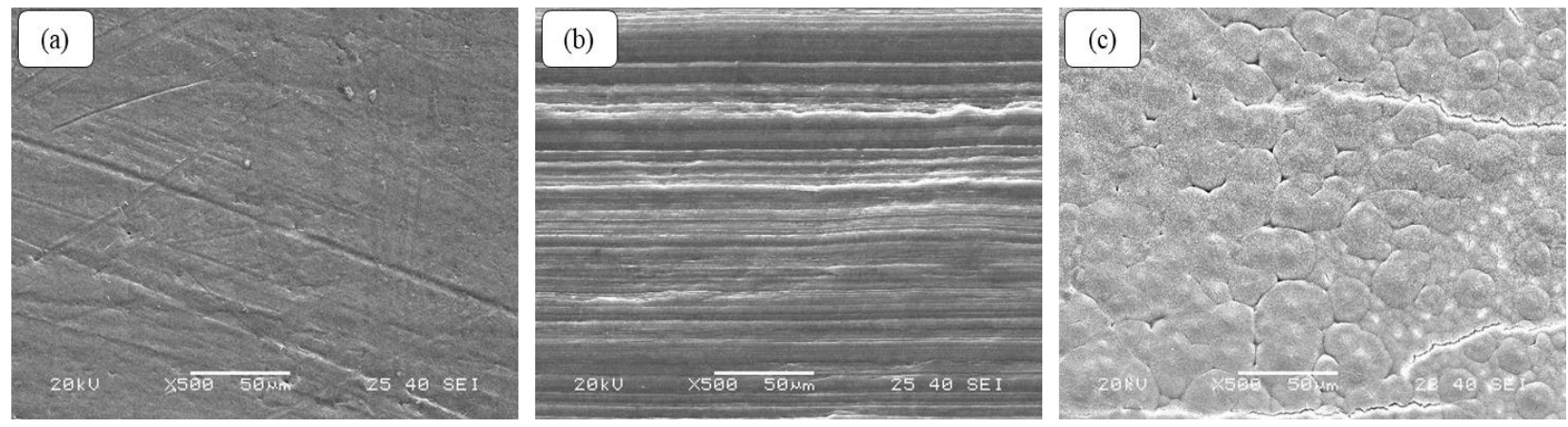

Fig. 2. SEM images of (a) pristine, (b) microstructured, and (c) micro-nanostructured surfaces.

To better understand the precise nature of the surface roughness, we relied on SEM images at a higher magnification of the replicated Teflon surface (Error! Reference source not found.a-c) and plasma-treated Teflon surface (Error! Reference source not found.d-f). The rice leaf-like grooves created on the replicated Teflon surface ranged widely in size, from several micrometers to tens of micrometers in width. The unidirectional patterns did not lead to anisotropic wettability properties for the microstructured Teflon surface, although such unidirectional patterns, e.g. rice leaves, usually show anisotropic rolling behavior [51]. The difference between $\mathrm{CAH}$ of the replicated Teflon surface in parallel and perpendicular groove direction was less than 5\% showing no significant difference in $\mathrm{CAH}$. This is logical as there are enough microstructures in between two adjacent grooves to establish a Cassie-Baxter wetting regime (See Error! Reference source not found.b, profilometry results). In contrast, lotus leaf-like patterns were created on the plasmatreated Teflon surfaces comprised of both micro and nanostructures. The nanostructures are superimposed on each microstructure in a lotus leaf-like pattern. This hierarchical structure produces the ultra-water-repellent properties of the plasma-treated Teflon surface. 

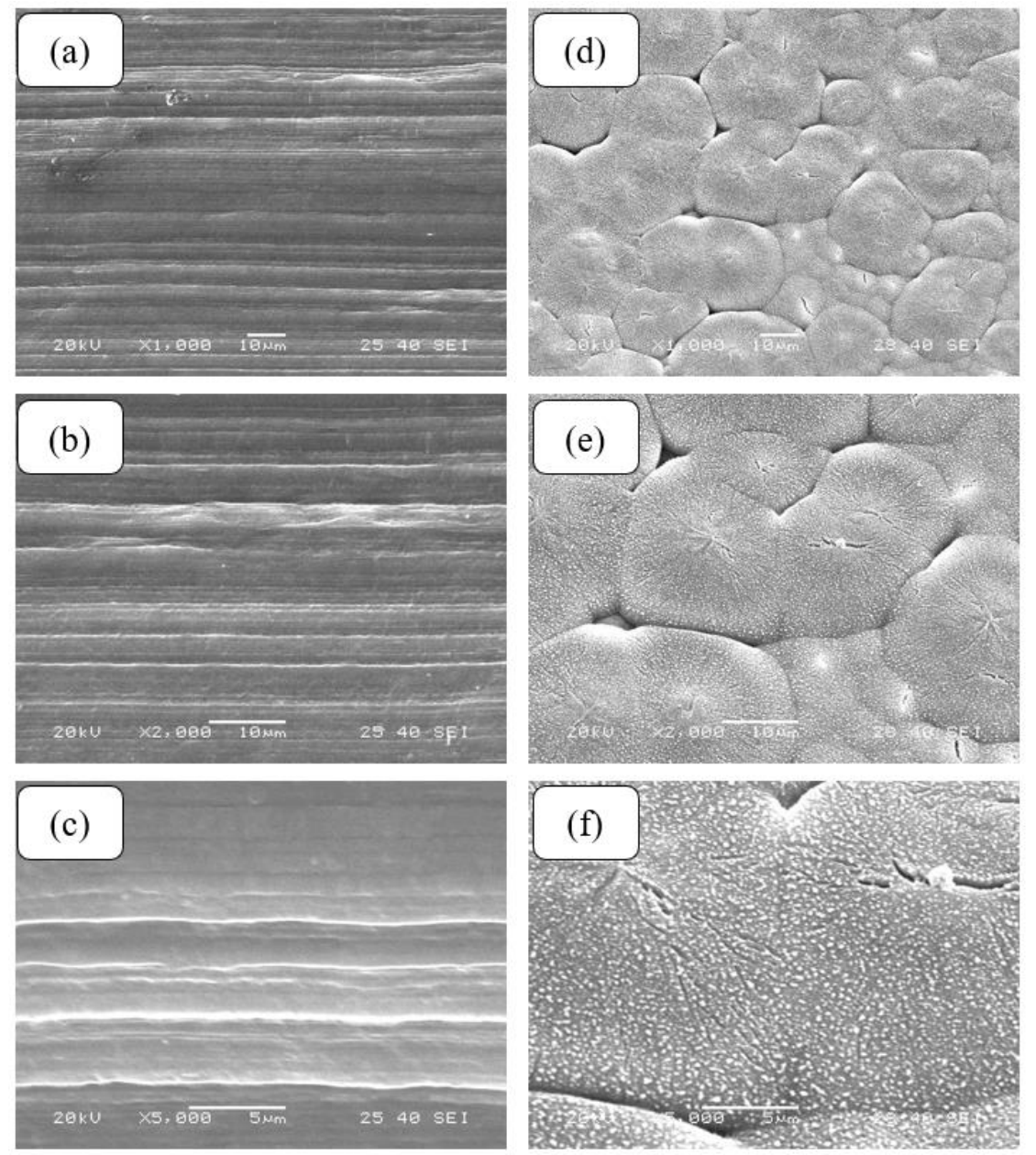

Fig. 3. SEM images of the microstructured surface at a (a) 1000×, (b) $2000 \times$, and (c) 5000× magnification; SEM images of the micro-nanostructured surface at (d) $1000 \times$, (e) $2000 \times$, and (f) $5000 \times$ magnification.

We applied a profilometry technique to evaluate the roughness of the pristine, replicated, and plasma-treated Teflon surfaces. We analyzed a $400 \times 400 \mu \mathrm{m}^{2}$ area of each surface (Error! Reference source not found.). Both 1D roughness (line roughness) and 2D roughness (area roughness) values are reported for comparison purposes (Table 1).

The root mean square of the replicated Teflon surface was significantly greater than that of the pristine Teflon surface $(5.88 \times$ for line roughness and $1.95 \times$ for area roughness), whereas the plasma treatment led to a remarkable reduction in surface roughness $(4.35 \times$ for line roughness and $9.80 \times$ for area roughness). The skewness coefficient $\left(S_{\mathrm{sk}}\right)$, which represents the degree of symmetry of the surface height about the mean plane [52], is lowest for the micro-nanostructured 
plasma-treated surface $\left(S_{\mathrm{sk}}=-0.15\right)$. It should be noted that zero skewness represents a fully symmetrical height distribution, positive skewness represents more peaks than valleys, and negative skewness indicates more valleys than peaks [53-55]. Consequently, via its decreased surface roughness, plasma treatment produced not only a smoother surface but also a more uniform surface where the height distribution was symmetric. This resulted in the occurrence of lotus leaflike micro-nanostructures. On the other hand, comparing the kurtosis coefficient $\left(\mathrm{S}_{\mathrm{ku}}\right)$ — describing the sharpness of the probability density of the profile [55] — of the three manufactured surfaces revealed that the microstructured surface $\left(S_{k u}>3\right)$ was a jagged surface having a relatively great number of high peaks and low valleys. The pristine and micro-nanostructured surfaces had a $\mathrm{S}_{\mathrm{ku}}<$ 3 and possessed a limited number of high peaks and low valleys.

The grooves observed in the SEM images were also evident in the replicated surface of the profilometry results. These grooves are responsible for the increase in the roughness values of the replicated surface. 

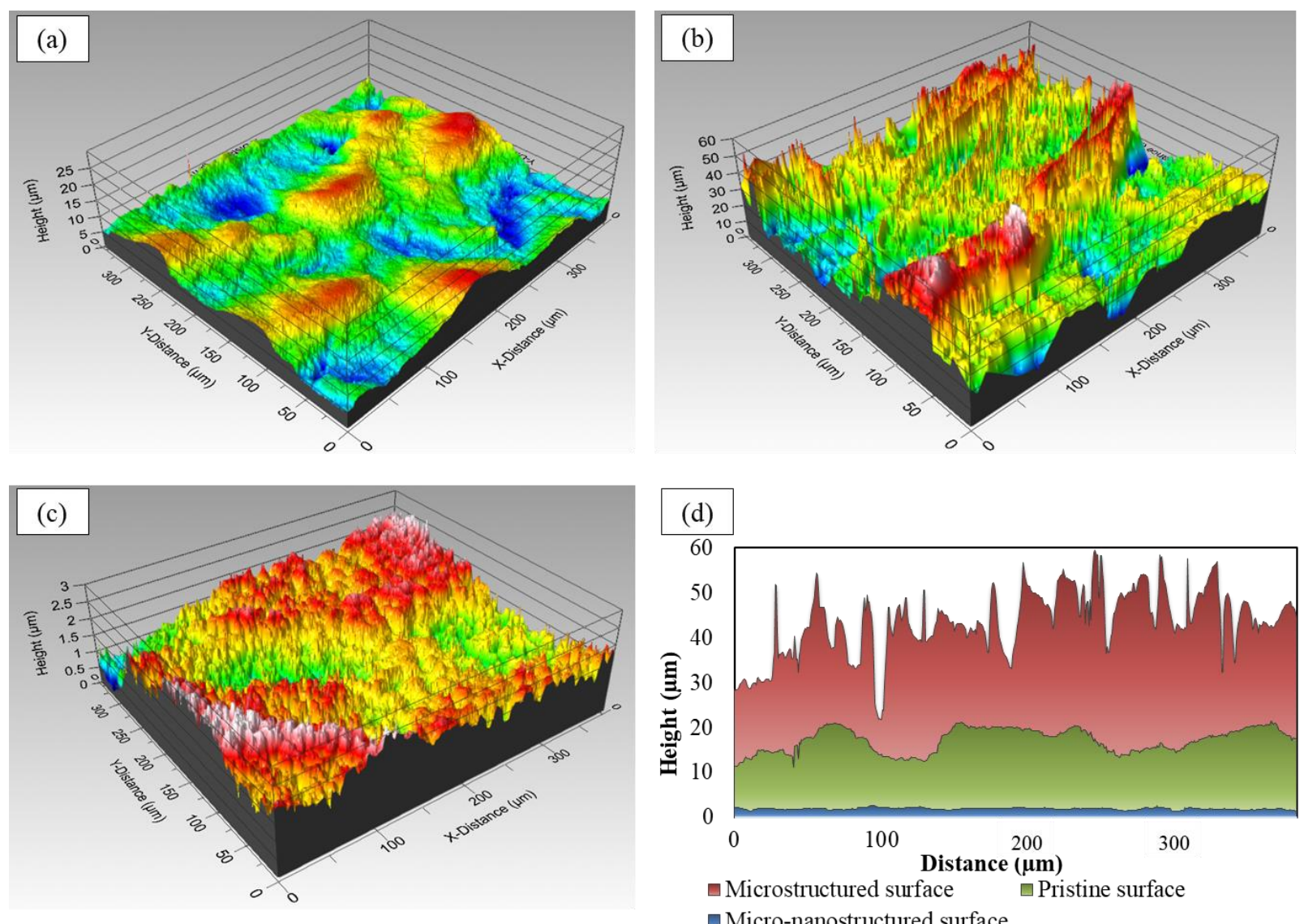

Fig. 4. 3D surface profiles of the (a) pristine, (b) microstructured, and (c) micro-nanostructured surfaces and (d) comparison of their 2D surface profiles.

Table 1. Area and line roughness values obtained from profilometry analysis.

\begin{tabular}{c}
\hline \\
\\
\hline Area roughness $(\mu \mathrm{m})$ \\
\hline Maximum peak to valley \\
height \\
$\left(S_{t}\right)$ \\
Arithmetic mean height \\
$\left(S_{a}\right)$ \\
Root mean square height \\
$\left(S_{q}\right)$ \\
Skewness \\
$\left(S_{s k}\right)$ \\
Kurtosis \\
$\left(S_{k u}\right)$ \\
\hline Line roughness $(\mu m)$ \\
\hline Maximum peak to valley \\
height
\end{tabular}

$\begin{array}{ccc}\text { Pristine } & \text { Microstructured } & \text { Micro- } \\ \text { surface } & \text { surface } & \text { nanostructured } \\ & & \text { surface }\end{array}$

44.78

59.08

3.54

3.60

6.68

0.36

4.41

8.58

0.45

0.47

0.48

$-0.15$

2.57

3.31

2.86

5.17

26.45

1.35 


\begin{tabular}{c|ccc}
$\begin{array}{c}\left(R_{t}\right) \\
\text { Arithmetic mean deviation } \\
\left(R_{a}\right)\end{array}$ & 0.60 & 3.39 & 0.13 \\
$\begin{array}{c}\text { Root mean square deviation } \\
\left(R_{q}\right)\end{array}$ & 0.74 & 4.35 & 0.17 \\
\hline
\end{tabular}

\subsection{Superhydrophobicity}

Pristine Teflon is a hydrophobic material having a WCA and CAH of $108.3^{\circ} \pm 1.7^{\circ}$ and $44^{\circ} \pm 2^{\circ}$, respectively. Both microstructured replicated and micro-nanostructured plasma-treated Teflon surfaces had a WCA of $>150^{\circ}$ and a $\mathrm{CAH}$ of $<10^{\circ}$ representing their superhydrophobic behavior (Table 2). Although the microstructured surface showed a slightly higher WCA than the micronanostructured surface, the $\mathrm{CAH}$ of the microstructured surface was higher; therefore, the roll-off properties of the micro-nanostructured surfaces was slightly better than that of the replicated microstructure surfaces (See Section 3.4).

Table 2. Water contact angle (WCA) and contact angle hysteresis (CAH) of pristine, microstructured, and micronanostructured surfaces.

\begin{tabular}{|c|c|c|c|}
\hline & Pristine surface & Microstructured surface & Micro-nanostructured surface \\
\hline$W C A\left(^{\circ}\right)$ & $108.3 \pm 1.7$ & $166.0 \pm 1.2$ & $163.2 \pm 0.8$ \\
\hline$C A H\left({ }^{\circ}\right)$ & $44 \pm 2$ & $4.2 \pm 1.1$ & $2.3 \pm 0.4$ \\
\hline
\end{tabular}

\subsection{Fourier transform infrared spectroscopy (FTIR)}

The chemical composition of the prepared superhydrophobic surfaces was assessed by means of ATR/FTIR spectroscopy. The FTIR spectra of the pristine Teflon surface was found to be identical to the produced superhydrophobic surfaces (Fig. 5). The two broad large absorption peaks observed around 1150 and $1200 \mathrm{~cm}^{-1}$ can be attributed to the asymmetric and symmetric $\mathrm{CF}_{2}$ stretching vibrations, respectively. The bands at 2349 and $1960 \mathrm{~cm}^{-1}$ can be assigned to a 
combination band associated with the $\mathrm{CF}_{2}$ backbone and terminal double bonds in the form of $-\mathrm{CF}=\mathrm{CF}_{2}[50,56]$. No additional peaks were observed in the FTIR spectrum of superhydrophobic surfaces. This confirms that there were neither hydroxyl bonds due to the reaction of Teflon with oxygen in the micro-nanostructured plasma-treated surface nor a reaction between the Teflon and aluminum substrate in the microstructured replicated surface. Thus, as the chemical composition of the Teflon surfaces was not altered by the treatment processes, the creation of surface roughness was the sole cause of the superhydrophobicity of the prepared surfaces.

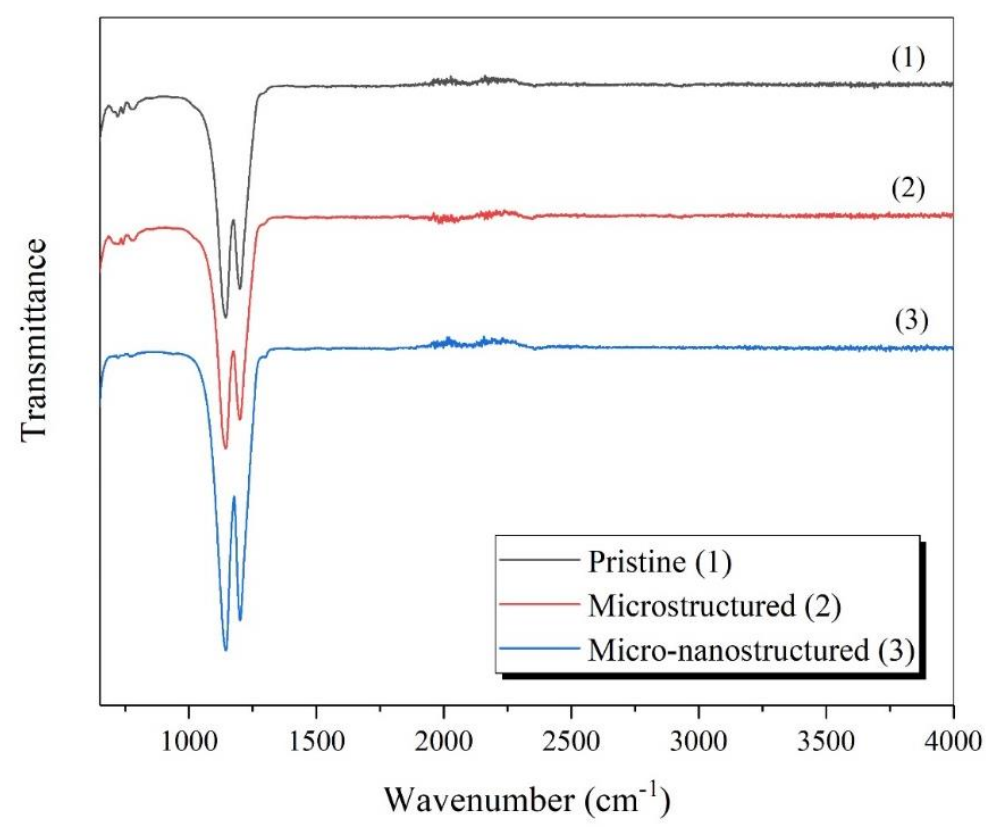

Fig. 5. FTIR spectra of the (1) pristine, (2) microstructured, and (3) micro-nanostructured surfaces.

\subsection{Water repellency properties}

Water droplets placed on the superhydrophobic Teflon surfaces rolled rapidly off the surface (Fig. 6). In contrast, the pristine Teflon surface was wetted easily by the water droplet, yet we observed no movement of the droplet on the surface. The water droplet rolled off the micro-nanostructured surface more quickly (average velocity of $16.6 \pm 0.1 \mathrm{~cm} \cdot \mathrm{s}^{-1}$ ) than the microstructured surface $(14.9$ $\left.\pm 0.2 \mathrm{~cm} \cdot \mathrm{s}^{-1}\right)$, a difference of $10.2 \%$. 
In sum, although microstructures replicated directly onto the Teflon surface led to a higher WCA, the microstructures also slowed water droplet movement across the surface. This pattern could also be predicted by the slightly higher $\mathrm{CAH}$ of the microstructure surface. The higher velocity of the water droplet on the plasma-treated Teflon surface can be related to the hierarchical structures, i.e. the presence of nanostructures superimposed on the microstructures. Although both microstructured and micro-nanostructured surfaces produced a WCA $>150^{\circ}$, Long et al. [57] showed that the sliding angle of micro-nanostructured surfaces is lower. The sliding angle of the microstructured surfaces increased considerably more than that of the micro-nanostructured surfaces due to the stronger adhesion of microstructured surfaces to water [57]. This greater water repellency of hierarchically structured surfaces has been observed in multiple studies [58-61].

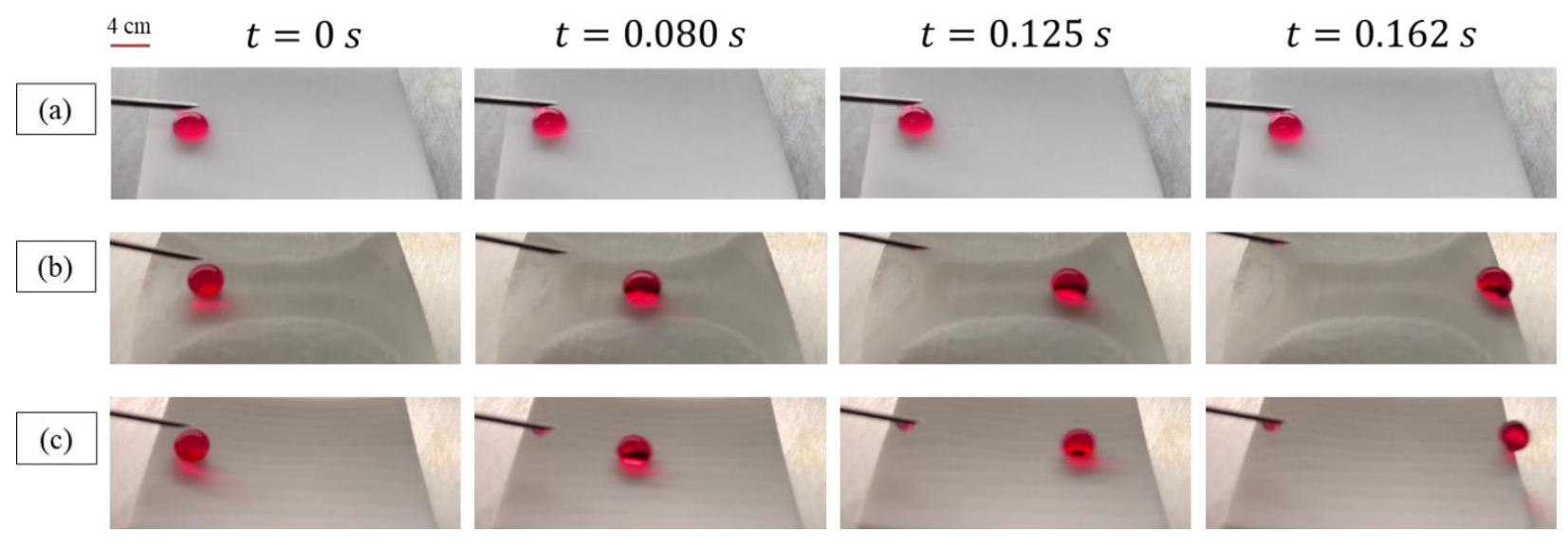

Fig. 6. Consecutive images of dyed water droplets leaving the (a) pristine, (b) microstructured, and (c) micronanostructured surfaces, demonstrating the water repellency of each surface.

\subsection{Water droplet impact}

For outdoor applications, the behavior of superhydrophobic surfaces must be assessed in relation to impact of raindrops. When a water droplet impacts a superhydrophobic surface, the spherical shape of the droplet is altered throughout four stages: contact, spreading, retraction or recoiling, and rebounding [62]. Following the initial contact, the spreading process occurs whereby energy 
is consumed through dissipation of the kinetic energy of the water droplet. The dissipation of kinetic energy takes place due to the impact, overcoming resistance from viscosity, and converting kinetic energy into surface energy. Therefore, the behavior of the solid surface is determined by the amount of energy dissipated, which is mostly defined by the surface properties. The portion of kinetic energy that is not dissipated during the spreading stage causes retraction and rebounding [63]. Finally, the water droplet ceases to rebound once all kinetic energy is dissipated from the droplet throughout the repeating rebounding stages, and the droplet then remains in place and does not move.

On the pristine Teflon surface, the water droplet rebounded partially off the surface (Fig. 7a). Due to its hydrophobicity and comparatively high surface adhesion, the water droplet's initial energy was dissipated, and it could not rebound fully from the surface. Once the water droplet impacted and spread fully across the microstructured surface, we observed a wavy interface between the air and water. This observation differed from that observed for the micro-nanostructured surface. This difference may be due to the high surface roughness of the microstructured surface relative to the micro-nanostructured surface [62].

On the superhydrophobic surfaces, the small amount of energy dissipation produced the retraction and rebounding stages. The retraction was observed immediately after the droplet reached its maximum spread diameter. The droplet bounced off the surfaces without being pinned onto them. At the beginning of the rebound stage, we observed a Worthington jet [64] (Fig. 7b-c), during which a droplet breaks up into a core droplet and some satellite droplets (see Videos S1 and S2). Both microstructured and micro-nanostructured surfaces had contact times of 17-19 ms (the time that the droplet is in contact with the surface before bouncing off [64]). 
We observed four rebounds on the microstructured surface; the maximum height of the droplet decreased steadily for each successive rebounding stage. The impacting droplet illustrated eight complete rebounds on the micro-nanostructured surface. The surface energy of microstructured and micro-nanostructured surfaces was $10.07 \pm 1.8 \mathrm{~mJ} \cdot \mathrm{m}^{-2}$ (dispersal: $8.15 \mathrm{~mJ} \cdot \mathrm{m}^{-2}$, polar: 1.91 $\mathrm{mJ} \cdot \mathrm{m}^{-2}$ ) and $6.08 \pm 0.9 \mathrm{~mJ} \cdot \mathrm{m}^{-2}$ (dispersal: $4.79 \mathrm{~mJ} \cdot \mathrm{m}^{-2}$, polar: $1.30 \mathrm{~mJ} \cdot \mathrm{m}^{-2}$ ) respectively, as measured by a contact angle measurement apparatus. Greater energy dissipation was expected for the microstructured surface due to its higher surface energy. The polar component of the surface energy was almost equal for both surfaces. Therefore, most of the difference between the microstructured and micro-nanostructured surfaces in terms of surface energy came from difference in their dispersal components. Apart from different surface energies of these surfaces, the different rebounding behaviors were also related to differences in surface roughness. Microstructured surfaces having deeper valleys allowed the water droplet to penetrate partially into the microstructures; thus, greater energy dissipation occurred. Hierarchical micronanostructures on a plasma-treated surface, however, ensured minimal contact between the droplet and the surface.

We confirmed the consistency of the Cassie-Baxter regime by observing droplets rebounding repeatedly on both superhydrophobic surfaces, and by observing that the water droplet did not become pinned to the surfaces until there was a complete dissipation of energy. 


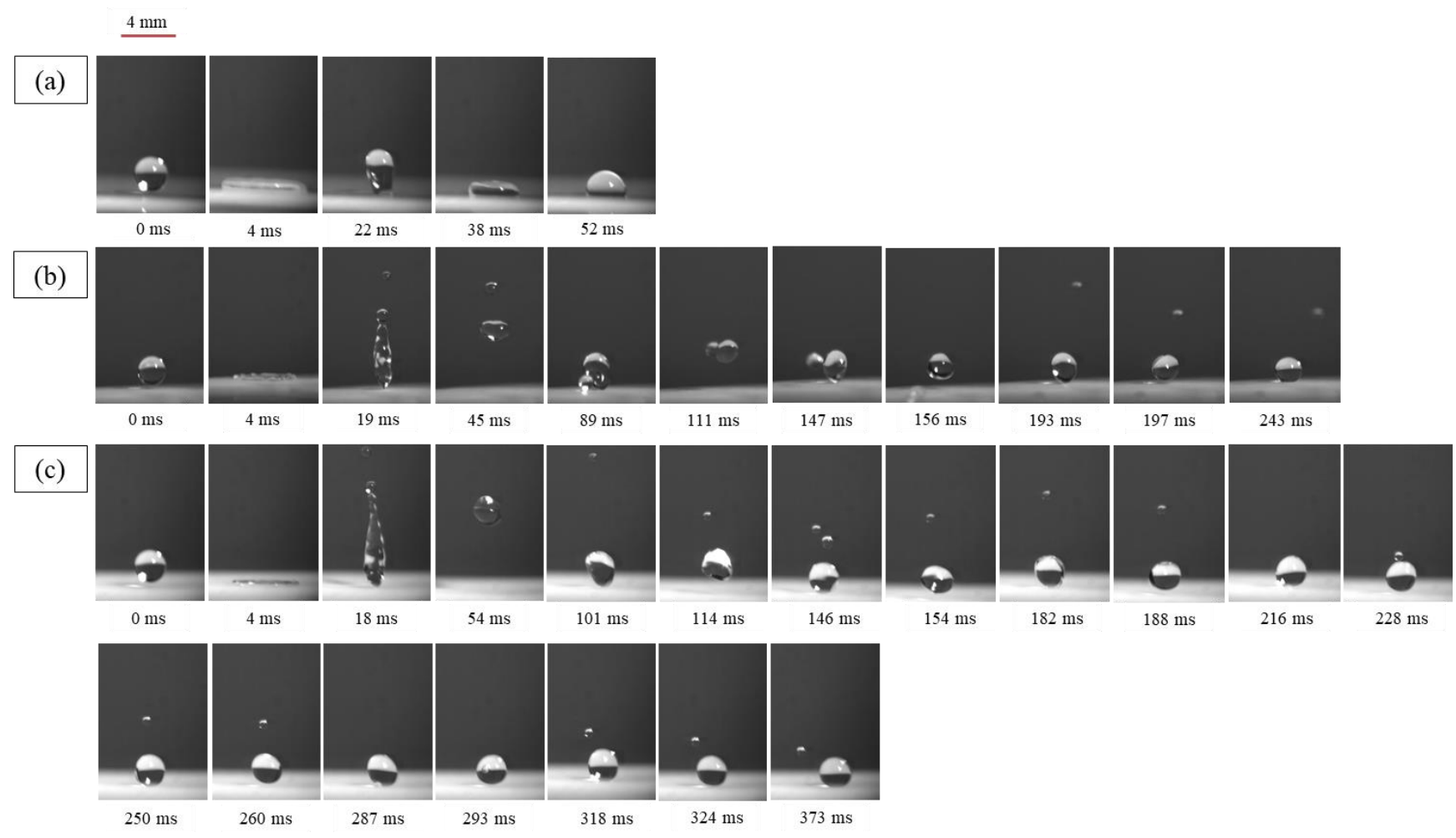

Fig. 7. Time-lapse imagery of a water droplet impacting a (a) pristine, (b) microstructured, and (c) micro-nanostructured surface.

\subsection{Icephobicity}

The extremely low surface energy of fluorinated polymers has made them an appealing candidate for water repellent and anti-icing applications. One of the more useful parameters for evaluating anti-icing properties is ice adhesion strength to the surface. In general, ice adhesion shear strength is measured via centrifuging an ice-covered sample [3,46, 65-67] or applying a tensile strength $[2,67,68]$ or push-off test $[20,67,69-72]$. Each approach can estimate the ice adhesion strength for a given surface [73]. We compared the measured ice adhesion strength and ice adhesion reduction factor of the superhydrophobic Teflon surfaces (ARF-STS) with those of a pristine Teflon surface (Fig. 8). ARF-STS is defined as the ratio between ice adhesion strength of the pristine Teflon surface and that of the produced superhydrophobic Teflon surface. The ice adhesion strength of the pristine Teflon surface was around $50 \mathrm{kPa}$, demonstrating its low ice 
adhesion strength compared to that of an uncoated aluminum substrate (the ice adhesion strength on bare aluminum alloy 6061 is $800-1072 \mathrm{kPa}[70,73]$ for deep freezer ice).

Whether superhydrophobicity enhances or reduces icephobicity has been a point of contention. Some studies have shown a reduction of ice adhesion strength on superhydrophobic surfaces $[65$, 74-76], whereas others have observed an increase [20, 73, 77, 78]. In this study, we observed an ice adhesion strength of ca. $18 \mathrm{kPa}$ for microstructured surfaces and ca. $9 \mathrm{kPa}$ for micronanostructured surfaces. These values are respectively $2.8 \times$ and $5.6 \times$ lower than the ice adhesion strength of the pristine Teflon surface. It can be claimed that the prepared Teflon surfaces having an ice adhesion strength $<20 \mathrm{kPa}$ are considered as appropriate surfaces for the passive removal of ice [9]. This pattern of ice adhesion strength can be explained by the high water repellency [73] of the surface and the presence of air pockets trapped among the micro- and nanostructures based on the Cassie-Baxter model [12, 20].

We also observed a positive correlation of $\mathrm{CAH}$ with ice adhesion strength as micronanostructured surfaces showed a lower CAH than microstructured surfaces. The correlation between $\mathrm{CAH}$ and ice adhesion strength on rough surfaces of similar chemistry has been observed previously [79]. The lower adhesion reduction factor (ARF) of microstructured surfaces compared to micro-nanostructured surfaces can be attributed to the mechanical interlocking of ice with the micro-scale grooves. This mechanical interlocking increases the contact area between the ice and the microstructures thereby increasing ice adhesion [77]. The ultra-pristine and uniform surface of the micro-nanostructured Teflon caused the least contact between the ice and the surface and thus produced the lowest ice adhesion strength. 


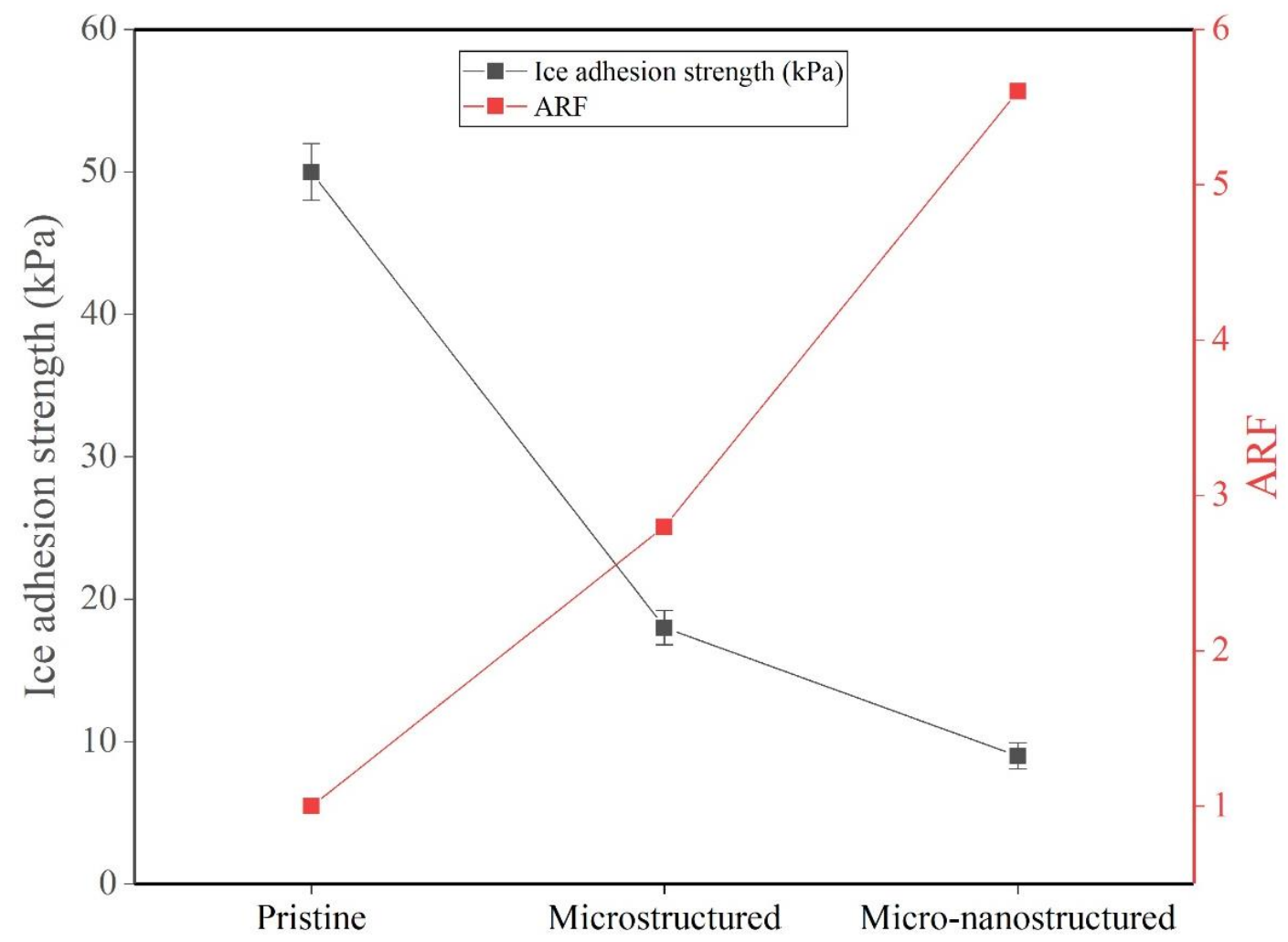

Fig. 8. Ice adhesion strength and adhesion reduction factor (ARF) for pristine, microstructured, and micronanostructured surfaces.

The delay in the onset of freezing, i.e. the initiation of water droplet freezing on the surface, also provides a good assessment of the icephobic behavior of the superhydrophobic surfaces. A superhydrophobic surface having a longer freezing delay has a greater anti-icing potential, i.e. less ice accumulation over time [80]. Surface roughness also affected considerably freezing delay; interestingly, these results differed from those obtained in the analysis of ice adhesion strength when freezing delay was assessed for the pristine, replicated, and plasma-treated Teflon surfaces at freezing temperatures of $-10^{\circ} \mathrm{C},-15^{\circ} \mathrm{C}$, and $-20^{\circ} \mathrm{C}$ (Table 3 ).

The freezing delay for the pristine Teflon surface was less than that for superhydrophobic surfaces due to the high contact area between the water droplet and the pristine Teflon surface caused by the lower WCA of the pristine Teflon surface. A large contact area means a high thermal 
conductivity leading to a short freezing delay for the pristine Teflon surface. Among the two superhydrophobic Teflon surfaces, the microstructured surface delayed freezing the longest. At all tested temperatures, water droplets placed on the microstructured surface froze markedly later than droplets on the micro-nanostructured surface. In the freezing process of a droplet on the surface, the micro-air pockets play the most important role because they act as thermal barriers to delay droplet freezing $[22,80]$. Thermodynamically speaking, the water droplet loses its energy according to $[15,81]$ :

$$
\delta Q=\rho_{w} C_{p}\left(t_{0}-t_{s}\right)=\Delta h . t
$$

where $\delta Q$ is the droplet's reduced energy, $\rho_{w}$ is the water density, $C_{p}$ is the water specific heat capacity, $t_{0}$ is the droplet's temperature at the initial point, $t_{s}$ is the droplet's final temperature, $\Delta h$ is heat loss of the water droplet over time, and $t$ is time. Considering $\delta Q$ as a constant value, a longer freezing time requires $\Delta h$ to be as small as possible. This can be obtained through the trapping of a large amount of air that can act as thermal insulation.

Thanks to the profilometry technique, we estimated the volume of trapped air for each surface. This approach is based on the total volume of the holes and voids within the asperities of each surface. If $v$ is defined as the ratio between the volume of the trapped air in the produced surface to that of the pristine surface, $v_{\text {microstructured }}$ and $v_{\text {micro-nanostructured }}$ are 3.93 and 0.11 , respectively. Therefore, the slower freezing process of the microstructured surface can be attributed to $\sim 11 \times$ more trapped air pockets within the microstructured surface than within the micro-nanostructured surface. It should be noted that the uniform nanostructures on the plasma-treated Teflon surface trapped even fewer air pockets than did the pristine Teflon surface. Nevertheless, the freezing delay tests showed that the micro-nanostructured surface delayed the onset of freezing more than 
the pristine surface. Although the superhydrophobic, micro-nanostructured surface had fewer pockets of trapped air, the minimal contact area between the water droplet and surface delayed the onset of freezing. The pristine hydrophobic surface having a rather larger water-surface contact area produced the quickest freezing process. Therefore, micro-air pockets have less influence on delaying freezing than water-surface contact area when comparing superhydrophobic and hydrophobic surfaces. In other words, the lower WCA of a hydrophobic surface is more important for freezing delay than a greater number of trapped air pockets.

Consequently, we observed that the delay in the freezing of a water droplet on microstructured surfaces was $\sim 2 \times$ longer than for micro-nanostructured surfaces and $\sim 4 \times$ longer than for pristine surfaces at all tested temperatures (Table 3).

Table 3. Freezing delay of the pristine, microstructured, and micro-nanostructured surfaces at various temperatures.

\begin{tabular}{llll}
\hline Temperature $\left({ }^{\circ} \mathrm{C}\right)$ & \multicolumn{2}{c}{ Freezing delay $(s)$} \\
\cline { 2 - 4 } & Pristine surface & $\begin{array}{l}\text { Microstructured } \\
\text { surface }\end{array}$ & $\begin{array}{l}\text { Micro-nanostructured } \\
\text { surface }\end{array}$ \\
\cline { 2 - 4 }-10 & $829 \pm 97$ & $3753 \pm 525$ & $1536 \pm 168$ \\
-15 & $395 \pm 36$ & $1632 \pm 131$ & $698 \pm 90$ \\
-20 & $160 \pm 19$ & $338 \pm 13$ & $231 \pm 28$ \\
\hline
\end{tabular}

\subsection{Self-cleaning properties}

The self-cleaning property of the produced Teflon surfaces was investigated using kaolin contaminant. We used a water droplet that was fixed to the syringe needle tip, to sweep the powder off the Teflon surfaces. On the pristine Teflon surface, the water droplet stuck to the contaminated kaolin-covered surface upon contact (Fig. 9 a-c). On both the microstructured (Fig. 9 d-f) and micro-nanostructured (Fig. $9 \mathrm{~g}-\mathrm{i}$ ) surfaces, no trace of the contaminant remained along the water droplet path following its passage across the surface. This is due to the greater adhesion of kaolin 
particles to the water droplet than to the superhydrophobic Teflon surfaces, benefiting from a low CAH. Therefore, kaolin particles easily adhere to the water droplet and are removed as the water droplet sweeps across the superhydrophobic surfaces.
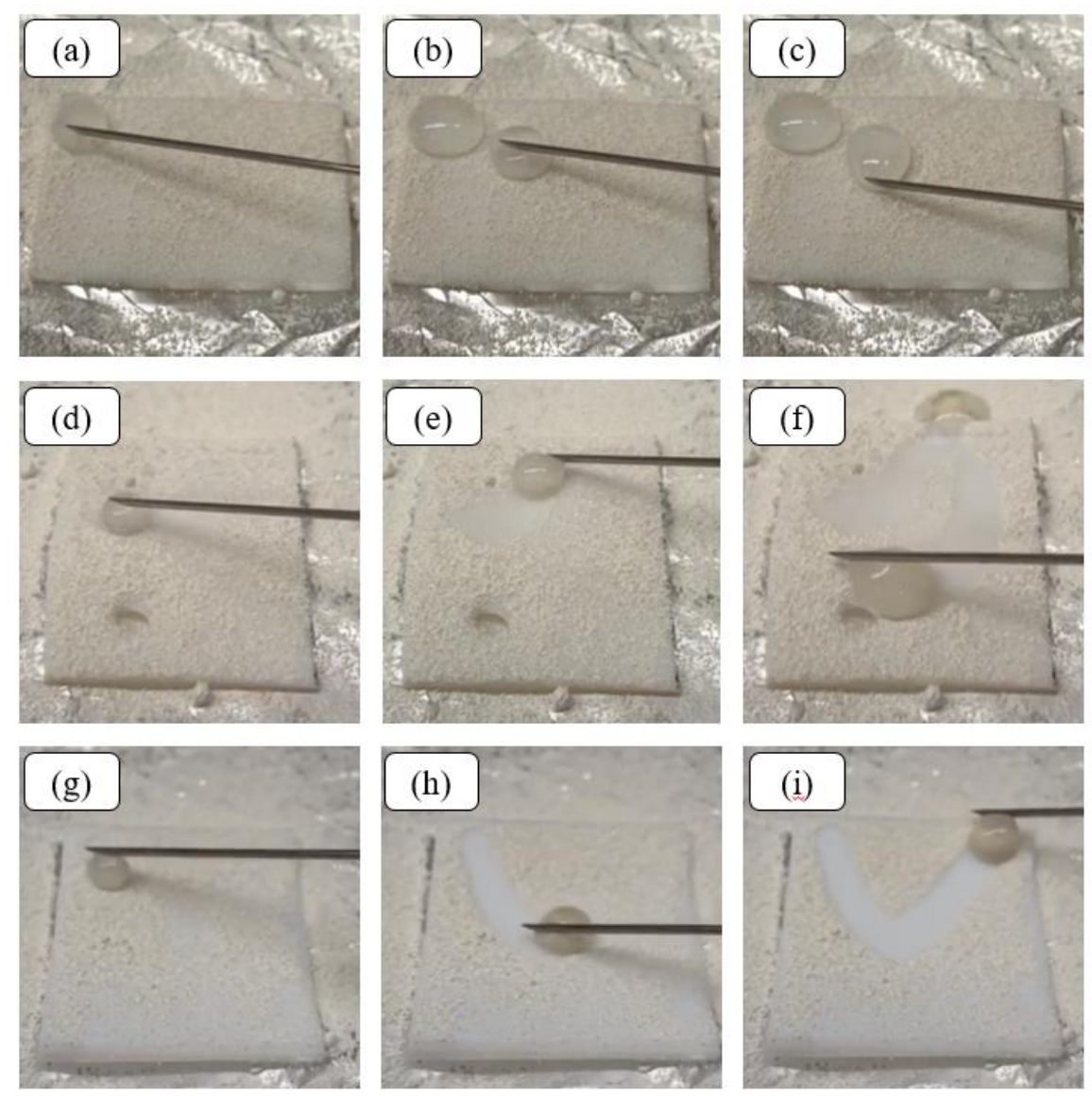

Fig. 9. Self-cleaning properties of the (a-c) pristine, (d-f) microstructured and (g-i) micro-nanostructured surfaces examined by water droplet sweeping.

On the pristine Teflon surface, the contaminant droplet, once dried, left a completely flat deposit, whereas on the superhydrophobic Teflon surfaces, the droplet maintained its initial spherical shape (Fig. 10b, f, and j). To evaluate the self-cleaning performance of the Teflon surfaces, water droplets were then applied to remove the deposited contaminants (Fig. 10c, g, and k). A single droplet was sufficient to remove thoroughly the dried contaminant from the superhydrophobic Teflon surfaces (Fig. 10h and 1) and all traces of the contaminant were removed from the superhydrophobic surfaces. However, the application of multiple water droplets could not remove the dried 
contaminants from the pristine Teflon surface; the contaminants were fixed onto the surface (Fig. 10d).
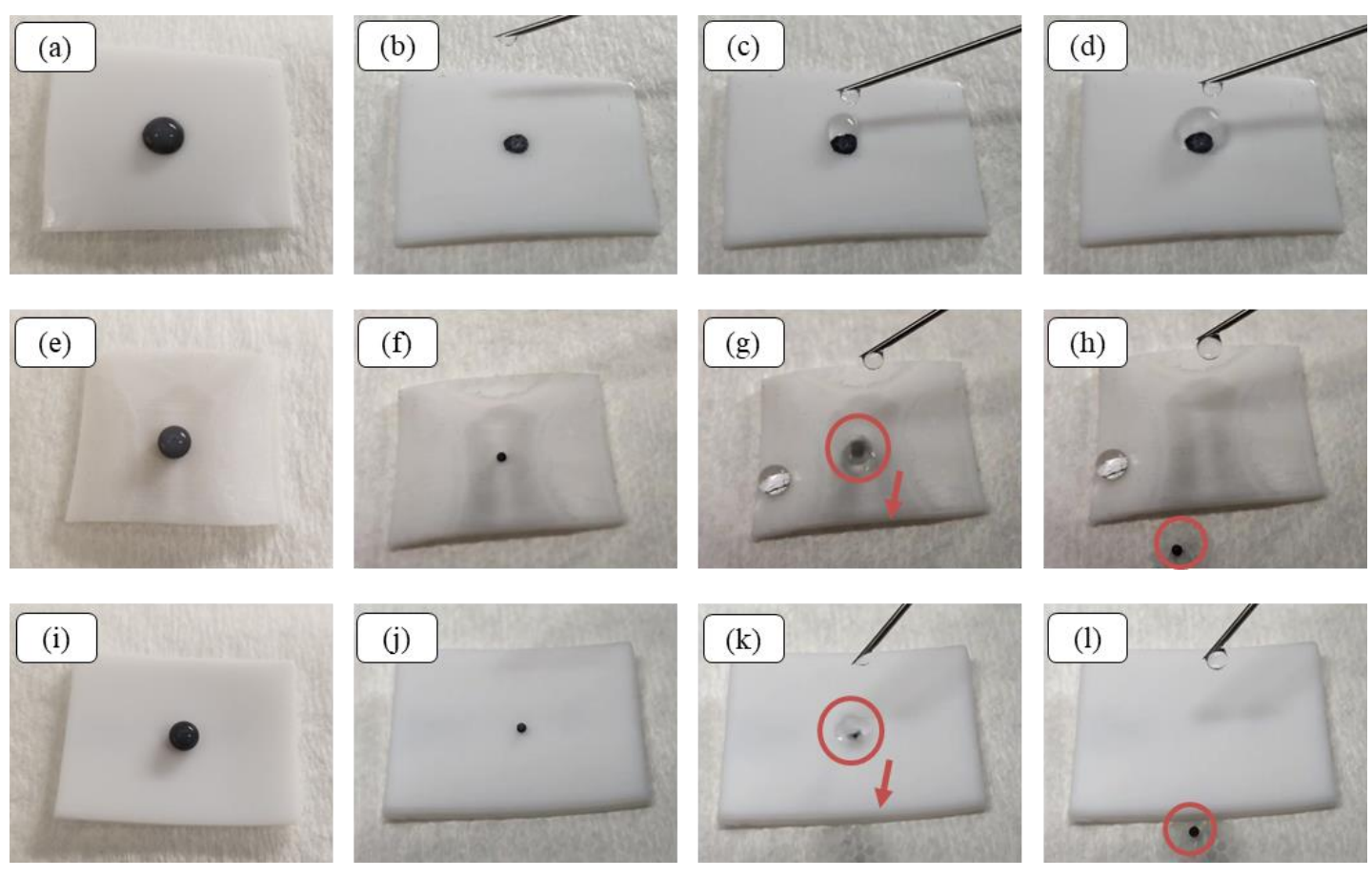

Fig. 10. Self-cleaning evaluation of (a-d) pristine, (e-h) microstructured, and (i-l) micro-nanostructured surfaces by observing of the cleaning of a dried contaminant solution using a water droplet.

\section{Conclusion}

We assessed the effects of surface roughness on water repellency, water droplet impact, ice adhesion strength, freezing delay, and self-cleaning properties of the superhydrophobic Teflon materials. The direct replication method resulted in microstructured rice leaf-like grooves having high peaks, whereas the atmospheric plasma treatment created hierarchical micro-nanostructured lotus leaf-like patterns. FTIR analysis showed that the produced superhydrophobic surfaces maintained spectra typical of Teflon, and thus neither method altered the chemical composition of the original Teflon surface. Although the microstructured surface had a higher WCA than the micro-nanostructured surface, the water droplets rolled off the micro-nanostructured surface slightly faster due to its lower $\mathrm{CAH}$. Moreover, the observed differences in the rebounding 
behavior of water droplets on the surfaces were due to the difference in surface energies as well as the difference in surface roughness. It also confirmed the consistency of the Cassie-Baxter regime on superhydrophobic surfaces. There was a significant reduction in ice adhesion strength of the microstructured and micro-nanostructured surfaces by a factor of $2.8 \times$ and $5.6 \times$, respectively. This confirmed that the microstructured surface, due to a greater contact area and mechanical interlocking, had higher ice adhesion than the micro-nanostructured surface. On the other hand, the deep grooves created on the microstructured surface produced a large amount of micro-air pockets ( $\sim \times$ more than the pristine surface). This resulted in a significant water droplet freezing delay at all tested temperatures. The fabricated surfaces also showed a self-cleaning capability, able to self-clean deposits of a wet and dry contaminant.

\section{Acknowledgments}

We want to thank Mr. Pierre Camirand and Mr. Yann Girard-Lachance for their technical collaboration.

\section{References}

[1] R. Jafari, G. Momen, and E. Eslami, "Fabrication of icephobic aluminium surfaces by atmospheric plasma jet polymerisation," Surface Engineering, pp. 1-6, 2018.

[2] M. Susoff, K. Siegmann, C. Pfaffenroth, and M. Hirayama, "Evaluation of icephobic coatingsScreening of different coatings and influence of roughness," Applied Surface Science, vol. 282, pp. 870-879, 2013.

[3] R. Menini, Z. Ghalmi, and M. Farzaneh, "Highly resistant icephobic coatings on aluminum alloys," Cold Regions Science Technology, vol. 65, no. 1, pp. 65-69, 2011. 
[4] G. Momen, R. Jafari, and M. Farzaneh, "Ice repellency behaviour of superhydrophobic surfaces: Effects of atmospheric icing conditions and surface roughness," Applied Surface Science, vol. 349, pp. 211-218, 2015.

[5] R. Jafari, G. Momen, and M. Farzaneh, "Durability enhancement of icephobic fluoropolymer film," Journal of Coatings Technology Research, vol. 13, no. 3, pp. 405-412, 2016.

[6] F. Wang, W. Ding, J. He, and Z. Zhang, "Phase transition enabled durable anti-icing surfaces and its DIY design," Chemical Engineering Journal, vol. 360, pp. 243-249, 2019.

[7] D. Chen, M. D. Gelenter, M. Hong, R. E. Cohen, and G. H. McKinley, "Icephobic surfaces induced by interfacial nonfrozen water," ACS applied materials interfaces, vol. 9, no. 4, pp. 4202-4214, 2017.

[8] Z. A. Janjua et al., "Performance and durability tests of smart icephobic coatings to reduce ice adhesion," Applied Surface Science, vol. 407, pp. 555-564, 2017.

[9] K. Golovin, S. P. Kobaku, D. H. Lee, E. T. DiLoreto, J. M. Mabry, and A. Tuteja, "Designing durable icephobic surfaces," Science Advances, vol. 2, no. 3, p. e1501496, 2016.

[10] R. Menini and M. Farzaneh, "Advanced icephobic coatings," Journal of adhesion science technology, vol. 25, no. 9, pp. 971-992, 2011.

[11] Y. Y. Yan, N. Gao, and W. Barthlott, "Mimicking natural superhydrophobic surfaces and grasping the wetting process: A review on recent progress in preparing superhydrophobic surfaces," Advances in colloid interface science, vol. 169, no. 2, pp. 80-105, 2011.

[12] A. Cassie and S. Baxter, "Wettability of porous surfaces," Transactions of the Faraday society, vol. 40, pp. 546-551, 1944.

[13] A. Alizadeh et al., "Dynamics of ice nucleation on water repellent surfaces," Langmuir, vol. 28, no. 6, pp. 3180-3186, 2012.

[14] P. Guo, Y. Zheng, M. Wen, C. Song, Y. Lin, and L. Jiang, "Icephobic/anti-icing properties of micro/nanostructured surfaces," Advanced Materials, vol. 24, no. 19, pp. 2642-2648, 2012. 
[15] Y. Shen, H. Tao, S. Chen, L. Zhu, T. Wang, and J. Tao, "Icephobic/anti-icing potential of superhydrophobic Ti6Al4V surfaces with hierarchical textures," RSC Advances, vol. 5, no. 3, pp. 1666-1672, 2015.

[16] C. Wei, B. Jin, Q. Zhang, X. Zhan, and F. Chen, "Anti-icing performance of super-wetting surfaces from icing-resistance to ice-phobic aspects: Robust hydrophobic or slippery surfaces," Journal of Alloys Compounds, vol. 765, pp. 721-730, 2018.

[17] E. J. Y. Ling, V. Uong, J.-S. b. Renault-Crispo, A.-M. Kietzig, and P. Servio, "Reducing ice adhesion on nonsmooth metallic surfaces: wettability and topography effects," ACS applied materials interfaces, vol. 8, no. 13, pp. 8789-8800, 2016.

[18] P. Hao, C. Lv, and X. Zhang, "Freezing of sessile water droplets on surfaces with various roughness and wettability," Applied physics letters, vol. 104, no. 16, p. 161609, 2014.

[19] P. Eberle, M. K. Tiwari, T. Maitra, and D. Poulikakos, "Rational nanostructuring of surfaces for extraordinary icephobicity," Nanoscale, vol. 6, no. 9, pp. 4874-4881, 2014.

[20] M. Zou, S. Beckford, R. Wei, C. Ellis, G. Hatton, and M. Miller, "Effects of surface roughness and energy on ice adhesion strength," Applied Surface Science, vol. 257, no. 8, pp. 3786-3792, 2011.

[21] Y. He, C. Jiang, X. Cao, J. Chen, W. Tian, and W. Yuan, "Reducing ice adhesion by hierarchical micro-nano-pillars," Applied Surface Science, vol. 305, pp. 589-595, 2014.

[22] K. Maghsoudi, G. Momen, R. Jafari, and M. Farzaneh, "Direct replication of micro-nanostructures in the fabrication of superhydrophobic silicone rubber surfaces by compression molding," Applied Surface Science, vol. 458, pp. 619-628, 2018.

[23] E. Vazirinasab, R. Jafari, and G. Momen, "Application of superhydrophobic coatings as a corrosion barrier: A review," Surface Coatings Technology, vol. 341, pp. 40-56, 2018.

[24] Y. Rahmawan, L. Xu, and S. Yang, "Self-assembly of nanostructures towards transparent, superhydrophobic surfaces," Journal of Materials Chemistry A, vol. 1, no. 9, pp. 2955-2969, 2013.

[25] M. Gong, X. Xu, Z. Yang, Y. Liu, H. Lv, and L. Lv, "A reticulate superhydrophobic self-assembly structure prepared by ZnO nanowires," Nanotechnology, vol. 20, no. 16, p. 165602, 2009. 
[26] J. Wu et al., "Rinse-resistant superhydrophobic block copolymer fabrics by electrospinning, electrospraying and thermally-induced self-assembly," Applied Surface Science, vol. 422, pp. 769$777,2017$.

[27] P. S. Brown and B. Bhushan, "Bioinspired, roughness-induced, water and oil super-philic and super-phobic coatings prepared by adaptable layer-by-layer technique," Scientific reports, vol. 5, p. 14030, 2015.

[28] D. Lopez-Torres, C. Elosua, M. Hernaez, J. Goicoechea, and F. Arregui, "From superhydrophilic to superhydrophobic surfaces by means of polymeric layer-by-layer films," Applied Surface Science, vol. 351, pp. 1081-1086, 2015.

[29] K. Feng, G.-Y. Hung, J. Liu, M. Li, C. Zhou, and M. Liu, "Fabrication of high performance superhydrophobic coatings by spray-coating of polysiloxane modified halloysite nanotubes," Chemical Engineering Journal, vol. 331, pp. 744-754, 2018.

[30] A. Zhuang et al., "Transparent superhydrophobic PTFE films via one-step aerosol assisted chemical vapor deposition," RSC Advances, vol. 7, no. 47, pp. 29275-29283, 2017.

[31] R. Tan et al., "A new approach to fabricate superhydrophobic and antibacterial low density isotropic pyrocarbon by using catalyst free chemical vapor deposition," Carbon, 2019.

[32] Y. Tang, Q. Zhang, X. Zhan, and F. Chen, "Superhydrophobic and anti-icing properties at overcooled temperature of a fluorinated hybrid surface prepared via a sol-gel process," Soft Matter, vol. 11, no. 22, pp. 4540-4550, 2015.

[33] Q. Li, Y. Yan, M. Yu, B. Song, S. Shi, and Y. Gong, "Synthesis of polymeric fluorinated sol-gel precursor for fabrication of superhydrophobic coating," Applied Surface Science, vol. 367, pp. 101108, 2016.

[34] J. Li, R. Wu, Z. Jing, L. Yan, F. Zha, and Z. Lei, "One-step spray-coating process for the fabrication of colorful superhydrophobic coatings with excellent corrosion resistance," Langmuir, vol. 31, no. 39, pp. 10702-10707, 2015. 
[35] E. Vazirinasab, R. Jafari, and G. Momen, "Wetting and Self-Cleaning Properties of Silicone Rubber Surfaces Treated by Atmospheric Plasma Jet," in 2018 IEEE Conference on Electrical Insulation and Dielectric Phenomena (CEIDP), 2018, pp. 239-242: IEEE.

[36] K. Maghsoudi, G. Momen, R. Jafari, M. Farzaneh, and T. Carreira, "Micro-Nanostructured Silicone Rubber Surfaces Using Compression Molding," in Materials Science Forum, 2018, vol. 941, pp. 1802-1807: Trans Tech Publ.

[37] K. Maghsoudi, R. Jafari, G. Momen, and M. Farzaneh, "Micro-nanostructured polymer surfaces using injection molding: A review," Materials today communications, vol. 13, pp. 126-143, 2017.

[38] E. Vazirinasab, R. Jafari, G. Momen, and T. Carreira, "Simple Fabrication of Superhydrophobic Surfaces Using Atmospheric-Pressure Plasma," in Materials Science Forum, 2018, vol. 941, pp. 1808-1814: Trans Tech Publ.

[39] K. Maghsoudi, G. Momen, R. Jafari, M. Farzaneh, and T. Carreira, "Micro-Nanostructured Silicone Surfaces for Highvoltage Application," in 2018 IEEE Conference on Electrical Insulation and Dielectric Phenomena (CEIDP), 2018, pp. 179-182: IEEE.

[40] Q. Zhao, Y. Liu, and S. Wang, "Surface modification of water treatment equipment for reducing CaSO4 scale formation," Desalination, vol. 180, no. 1-3, pp. 133-138, 2005.

[41] P. Van Der Wal and U. Steiner, "Super-hydrophobic surfaces made from Teflon," Soft Matter, vol. 3, no. 4, pp. 426-429, 2007.

[42] J. Zhang, J. Li, and Y. Han, "Superhydrophobic PTFE surfaces by extension," Macromolecular Rapid Communications, vol. 25, no. 11, pp. 1105-1108, 2004.

[43] D. Song, R. J. Daniello, and J. P. Rothstein, "Drag reduction using superhydrophobic sanded Teflon surfaces," Experiments in fluids, vol. 55, no. 8, p. 1783, 2014.

[44] M. A. Nilsson, R. J. Daniello, and J. P. Rothstein, "A novel and inexpensive technique for creating superhydrophobic surfaces using Teflon and sandpaper," Journal of Physics D: Applied Physics, vol. 43, no. 4, p. 045301, 2010. 
[45] R. Jafari, S. Asadollahi, and M. Farzaneh, "Applications of plasma technology in development of superhydrophobic surfaces," Plasma Chemistry and Plasma Processing, vol. 33, no. 1, pp. 177200, 2013.

[46] R. Jafari, R. Menini, and M. Farzaneh, "Superhydrophobic and icephobic surfaces prepared by RFsputtered polytetrafluoroethylene coatings," Applied Surface Science, vol. 257, no. 5, pp. 1540$1543,2010$.

[47] R. Jafari and M. Farzaneh, "Fabrication of superhydrophobic nanostructured surface on aluminum alloy," Applied Physics A, vol. 102, no. 1, pp. 195-199, 2011.

[48] D. Jucius et al., "Hot embossing of PTFE: towards superhydrophobic surfaces," Applied Surface Science, vol. 257, no. 6, pp. 2353-2360, 2011.

[49] T. Takahashi et al., "Change in surface morphology of polytetrafluoroethylene by reactive ion etching," Radiation Physics and Chemistry, vol. 80, no. 2, pp. 253-256, 2011.

[50] S. Zanini, R. Bami, R. Della Pergola, and C. Riccardi, "Development of super-hydrophobic PTFE and PET surfaces by means of plasma processes," in Journal of Physics: Conference Series, 2014, vol. 550, no. 1, p. 012029: IOP Publishing.

[51] S. G. Lee, H. S. Lim, D. Y. Lee, D. Kwak, and K. Cho, "Tunable anisotropic wettability of rice leaf-like wavy surfaces," Advanced Functional Materials, vol. 23, no. 5, pp. 547-553, 2013.

[52] M. Merola, A. Ruggiero, J. S. De Mattia, and S. J. M. Affatato, "On the tribological behavior of retrieved hip femoral heads affected by metallic debris. A comparative investigation by stylus and optical profilometer for a new roughness measurement protocol," vol. 90, pp. 365-371, 2016.

[53] A. Canabarro, F. Figueiredo, S. Paciornik, and G. J. S. T. J. o. S. M. De-Deus, "Two-and threedimensional profilometer assessments to determine titanium roughness," vol. 31, no. 4, pp. 174179, 2009.

[54] M. Sedlaček, B. Podgornik, and J. J. T. i. Vižintin, "Correlation between standard roughness parameters skewness and kurtosis and tribological behaviour of contact surfaces," vol. 48, pp. 102$112,2012$. 
[55] E. Gadelmawla, M. Koura, T. Maksoud, I. Elewa, and H. J. J. o. M. P. T. Soliman, "Roughness parameters," vol. 123, no. 1, pp. 133-145, 2002.

[56] A. Galante, O. Galante, and L. Campos, "Study on application of PTFE, FEP and PFA fluoropolymers on radiation dosimetry," Nuclear Instruments, Methods in Physics Research Section A: Accelerators, Spectrometers, Detectors Associated Equipment, vol. 619, no. 1-3, pp. 177-180, 2010.

[57] J. Long et al., "Cassie-state stability of metallic superhydrophobic surfaces with various micro/nanostructures produced by a femtosecond laser," Langmuir, vol. 32, no. 4, pp. 1065-1072, 2016.

[58] B. Bhushan, Y. C. Jung, and K. Koch, "Micro-, nano-and hierarchical structures for superhydrophobicity, self-cleaning and low adhesion," Philosophical Transactions of the Royal Society of London A: Mathematical, Physical and Engineering Sciences, vol. 367, no. 1894, pp. 1631-1672, 2009.

[59] Y. Shen et al., "Water repellency of hierarchical superhydrophobic Ti6Al4V surfaces improved by secondary nanostructures," Applied Surface Science, vol. 321, pp. 469-474, 2014.

[60] D. Wu et al., "Facile creation of hierarchical PDMS microstructures with extreme underwater superoleophobicity for anti-oil application in microfluidic channels," Lab on a Chip, vol. 11, no. 22, pp. 3873-3879, 2011.

[61] K. Mielonen, M. Suvanto, and T. Pakkanen, "Curved hierarchically micro-micro structured polypropylene surfaces by injection molding," Journal of Micromechanics and Microengineering, vol. 27, no. 1, p. 015025, 2016.

[62] P. Hao, C. Lv, F. Niu, and Y. Yu, "Water droplet impact on superhydrophobic surfaces with microstructures and hierarchical roughness," Science China Physics, Mechanics Astronomy, vol. 57, no. 7, pp. 1376-1381, 2014. 
[63] Y. Wang, J. Xue, Q. Wang, Q. Chen, and J. Ding, "Verification of icephobic/anti-icing properties of a superhydrophobic surface," ACS applied materials interfaces, vol. 5, no. 8, pp. 3370-3381, 2013.

[64] L. Chen, Z. Xiao, P. C. Chan, and Y.-K. Lee, "Static and dynamic characterization of robust superhydrophobic surfaces built from nano-flowers on silicon micro-post arrays," Journal of micromechanics microengineering, vol. 20, no. 10, p. 105001, 2010.

[65] S. Kulinich and M. Farzaneh, "Ice adhesion on super-hydrophobic surfaces," Applied Surface Science, vol. 255, no. 18, pp. 8153-8157, 2009.

[66] H. Niemelä-Anttonen et al., "Icephobicity of Slippery Liquid Infused Porous Surfaces under Multiple Freeze-Thaw and Ice Accretion-Detachment Cycles," Advanced Materials Interfaces, vol. 5, no. 20, p. 1800828, 2018.

[67] A. Work and Y. Lian, "A critical review of the measurement of ice adhesion to solid substrates," Progress in Aerospace Sciences, 2018.

[68] S. Yang, Q. Xia, L. Zhu, J. Xue, Q. Wang, and Q.-m. Chen, "Research on the icephobic properties of fluoropolymer-based materials," Applied Surface Science, vol. 257, no. 11, pp. 4956-4962, 2011.

[69] X. Li, Y. Zhao, H. Li, and X. Yuan, "Preparation and icephobic properties of polymethyltrifluoropropylsiloxane-polyacrylate block copolymers," Applied Surface Science, vol. 316, pp. 222-231, 2014.

[70] R. Dou et al., "Anti-icing coating with an aqueous lubricating layer," ACS applied materials \& interfaces, vol. 6, no. 10, pp. 6998-7003, 2014.

[71] C. Wang, W. Zhang, A. Siva, D. Tiea, and K. J. Wynne, "Laboratory test for ice adhesion strength using commercial instrumentation," Langmuir, vol. 30, no. 2, pp. 540-547, 2014.

[72] X. Wu, X. Zhao, J. W. C. Ho, and Z. Chen, "Design and durability study of environmental-friendly room-temperature processable icephobic coatings," Chemical Engineering Journal, vol. 355, pp. 901-909, 2019. 
[73] T. Bharathidasan, S. V. Kumar, M. Bobji, R. Chakradhar, and B. J. Basu, "Effect of wettability and surface roughness on ice-adhesion strength of hydrophilic, hydrophobic and superhydrophobic surfaces," Applied Surface Science, vol. 314, pp. 241-250, 2014.

[74] R. Menini and M. Farzaneh, "Elaboration of Al2O3/PTFE icephobic coatings for protecting aluminum surfaces," Surface and Coatings Technology, vol. 203, no. 14, pp. 1941-1946, 2009.

[75] G. Momen, M. Farzaneh, and R. Jafari, "Wettability behaviour of RTV silicone rubber coated on nanostructured aluminium surface," Applied Surface Science, vol. 257, no. 15, pp. 6489-6493, 2011.

[76] R. Menini, Z. Ghalmi, and M. Farzaneh, "Highly resistant icephobic coatings on aluminum alloys," Cold Regions Science and Technology, vol. 65, no. 1, pp. 65-69, 2011.

[77] K. K. Varanasi, T. Deng, J. D. Smith, M. Hsu, and N. Bhate, "Frost formation and ice adhesion on superhydrophobic surfaces," Applied Physics Letters, vol. 97, no. 23, p. 234102, 2010.

[78] J. Chen et al., "Superhydrophobic surfaces cannot reduce ice adhesion," Applied Physics Letters, vol. 101, no. 11, p. 111603, 2012.

[79] S. Kulinich and M. Farzaneh, "How wetting hysteresis influences ice adhesion strength on superhydrophobic surfaces," Langmuir, vol. 25, no. 16, pp. 8854-8856, 2009.

[80] Q. Yang et al., "Air cushion convection inhibiting icing of self-cleaning surfaces," ACS applied materials interfaces, vol. 8, no. 42, pp. 29169-29178, 2016.

[81] J. Yang and W. Li, "Preparation of superhydrophobic surfaces on Al substrates and the anti-icing behavior," Journal of Alloys Compounds, vol. 576, pp. 215-219, 2013. 